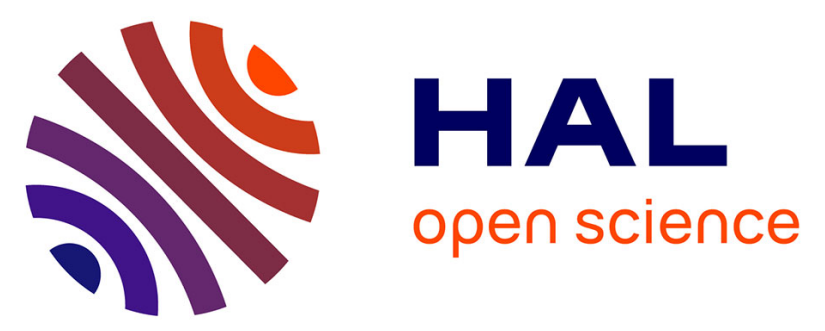

\title{
Co-occurrence of fumonisins with aflatoxins in home stored maize for human consumption in rural villages of Tanzania
}

Martin Epafras Kimanya, Bruno de Meulenaer, Bendantinguka Tiisekwa, Frank Devlieghere, Margareth Ndomondo-Sigonda, John van Camp, Patrick

\author{
W Kolsteren
}

\section{To cite this version:}

Martin Epafras Kimanya, Bruno de Meulenaer, Bendantinguka Tiisekwa, Frank Devlieghere, Margareth Ndomondo-Sigonda, et al.. Co-occurrence of fumonisins with aflatoxins in home stored maize for human consumption in rural villages of Tanzania. Food Additives and Contaminants, 2008, 25 (11), pp.1353-1364. 10.1080/02652030802112601 . hal-00577391

\section{HAL Id: hal-00577391 https://hal.science/hal-00577391}

Submitted on 17 Mar 2011

HAL is a multi-disciplinary open access archive for the deposit and dissemination of scientific research documents, whether they are published or not. The documents may come from teaching and research institutions in France or abroad, or from public or private research centers.
L'archive ouverte pluridisciplinaire HAL, est destinée au dépôt et à la diffusion de documents scientifiques de niveau recherche, publiés ou non, émanant des établissements d'enseignement et de recherche français ou étrangers, des laboratoires publics ou privés. 


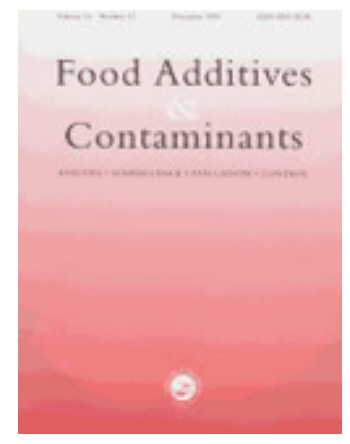

\section{Co-occurrence of fumonisins with aflatoxins in home stored maize for human consumption in rural villages of Tanzania}

\begin{tabular}{|r|l|}
\hline Journal: & Food Additives and Contaminants \\
\hline Manuscript ID: & TFAC-2007-381.R1 \\
\hline Manuscript Type: & Original Research Paper \\
\hline Author: & $14-$ Mar-2008 \\
\hline Complete List of Authors: & $\begin{array}{l}\text { Kimanya, Martin; Tanzania Food and Drugs Authority, Food safety; } \\
\text { Ghent University, Food Safety and Food Quality } \\
\text { De Meulenaer, Bruno; Ghent University, Food Safety and Food } \\
\text { Quality } \\
\text { Tiisekwa, Bendantinguka; Sokoine University of Agriculture, Food } \\
\text { Science and Technology } \\
\text { Devlieghere, Frank; Ghent University, Food Safety and Food Quality } \\
\text { Ndomondo-Sigonda, Margareth; Tanzania Food and Drugs Authority } \\
\text { Van Camp, John; Ghent University, Food Safety and Food Quality } \\
\text { Kolsteren, Patrick; Institute of Tropical Medicine, Public Health; } \\
\text { Ghent University, Food Safety and Food Quality }\end{array}$ \\
\hline Methods/Techniques: & Chromatography - HPLC \\
\hline Additives/Contaminants: & Aflatoxins, Fumonisins \\
\hline Food Types: & maize \\
\hline & \\
\hline
\end{tabular}

\section{SCHOLARONE Manuscripts}


1 Co-occurrence of fumonisins with aflatoxins in home stored maize for

\section{2 human consumption in rural villages of Tanzania}

3

4

$5 \quad$ Martin E. Kimanya ${ }^{1,2}$, Bruno De Meulenaer ${ }^{2}$, Bendantunguka Tiisekwa ${ }^{3}$

6 Margareth Ndomondo-Sigonda ${ }^{1}$, Frank Devlieghere ${ }^{2}$, John Van Camp ${ }^{2}$ and Patrick

7 Kolsteren ${ }^{2,4}$

8

9

$10{ }^{1}$ Tanzania Food and Drugs Authority, P. O. Box 77150, Dar es Salaam, Tanzania'

$11{ }^{2}$ Department of Food Safety and Food Quality, Faculty of Bioscience Engineering,

12 Ghent University, Coupure links 653, B-9000 Ghent-Belgium.

$13{ }^{3}$ Department of Food Science and Technology, Sokoine University of Agriculture, P. O.

14 Box 3006 Morogoro, Tanzania.

$15{ }^{4}$ Nutrition Unit, Department of Public Health, Institute of Tropical Medicine,

16 Nationalestraat 155, B-2000 Antwerpen, Belgium

18 Keywords:

19 Aflatoxins, Co-occurrence, Fumonisins, Home stored maize, Tanzania 


\section{Abstract}

3 This study determined maize-user practices that influence the presence of fumonisin

4 and aflatoxin contamination of maize in food consumed in the rural areas of Tanzania.

5 Samples of the 2005 maize harvest in Tanzania were collected from 120 households

6 and examined for fumonisins and aflatoxins. Information on whether the maize was

7 sorted to remove defective (visibly damaged or mouldy) maize prior to storage and

8 whether the damaged and mouldy maize or the non-dehulled maize was used as food

9 was also collected. Also, the percentage of defective kernels in the samples was

10 determined. Ninety percent of the households sorted out defective maize, $53 \%$

11 consumed the defective maize and $30 \%$ consumed non-dehulled maize. In $52 \%$ of the

12 samples, fumonisins were determined at levels up to $11,048 \mu \mathrm{g} / \mathrm{kg}$ (median, $363 \mu \mathrm{g} / \mathrm{kg}$ )

13 and in $15 \%$ exceeded $1000 \mu \mathrm{g} / \mathrm{kg}$; the maximum limit (ML) for fumonisins in maize for

14 human consumption in other countries. Aflatoxins were detected in $18 \%$ of the samples

15 at levels up to $158 \mu \mathrm{g} / \mathrm{kg}$ (median, $24 \mu \mathrm{g} / \mathrm{kg}$ ). $12 \%$ of the samples exceeded the

16 Tanzanian limit for total aflatoxins $(10 \mu \mathrm{g} / \mathrm{kg})$. Aflatoxins co-occurred with fumonisins

17 in $12 \%$ of the samples. The percentage defective kernels (mean, 22\%) correlated

18 positively $(\mathrm{r}=0.39)$ with the fumonisin levels. Tanzanians are at risk of exposure to

19 fumonisins and aflatoxins in maize. There is a need for further research on fumonisin

20 and aflatoxin exposure in Tanzania to develop appropriate control strategies. 
1 Introduction

2 Maize is a staple food for people living in sub-Saharan Africa, particularly those living

3 in the rural areas. The cereal is frequently contaminated with fumonisins (Shephard et

4 al. 1996, Miller 1995) and aflatoxins (Miller 1995). Visibly damaged and mouldy

5 maize contains more fumonisins and aflatoxins compared to visibly good quality maize

6 (Fandohan et al. 2005, Kpodo et al. 2000, Sydenham et al. 1990). The fumonisins of

7 agricultural and health importance are fumonisin $\mathrm{B}_{1}\left(\mathrm{FB}_{1}\right)$, fumonisin $\mathrm{B}_{2}\left(\mathrm{FB}_{2}\right)$ and

8 fumonisin $\mathrm{B}_{3}\left(\mathrm{FB}_{3}\right)$ (Miller 1995, Doko and Visconti 1994). Studies in animals

9 demonstrate that fumonisin $\mathrm{B}_{1}\left(\mathrm{FB}_{1}\right)$ causes liver cancer in male $\mathrm{BD}$ IX rats and female

10 B6C3F1 mice and kidney cancer in male Fischer 344 rats (International Agency for

11 Research in Cancer (IARC), 2002). In humans, $\mathrm{FB}_{1}$ has been epidemiologically

12 associated with high rates of oesophageal cancer reported in the former Transkei region

13 of South Africa (Rheeder et al. 1992) and in China (Wang et al. 2000;, Chu and Li

14 1994). The International Agency for Research on Cancer (IARC) declared $\mathrm{FB}_{1}$ as group

15 2B carcinogen; possibly carcinogenic to man. The Joint FAO/WHO Expert Committee

16 on Food Additives (JECFA) assigned a provisional maximum tolerable daily intake

17 (PMTDI) of $2 \mu \mathrm{g} / \mathrm{kg}$ bw/d for $\mathrm{FB}_{1}, \mathrm{FB}_{2}$ and $\mathrm{FB}_{3}$, alone or in combination (WHO 2002).

19 Aflatoxins of public health importance that occur naturally in cereals exist in four

20 forms, namely aflatoxin $\mathrm{B}_{1}\left(\mathrm{AFB}_{1}\right), \mathrm{B}_{2}\left(\mathrm{AFB}_{2}\right), \mathrm{G}_{1}\left(\mathrm{AFG}_{1}\right)$ and $\mathrm{G}_{2}\left(\mathrm{AFG}_{2}\right)$ with $\mathrm{AFB}_{1}$

21 being the most potent form of the aflatoxins (International Agency for Research on

22 Cancer [IARC] 1993). These toxins are acutely toxic, immunosuppressive, mutagenic,

23 teratogenic, and carcinogenic. 
2 Fumonisins and aflatoxins have a widespread occurrence in maize worldwide. In Africa,

3 fumonisins in maize have been extensively studied in South Africa (Shephard et al.

4 2007, Shephard et al. 1996, Sydenham et al. 1990). Reports are also available on the

5 presence of fumonisins in other African countries including Kenya (Kadera et al. 1999),

6 Benin (Fandohan et al. 2006), Ghana (Kpodo et al. 2000) and Zimbabwe (Gamanya

7 and Sibanda 2001). Doko et al. (1996) detected fumonisins in 92.5\% of maize samples

8 from Eastern and Southern Africa (including 9 samples from Tanzania) suggesting a

9 widespread occurrence of the toxins in that region. Also widespread occurrence of

10 aflatoxins in maize has been reported in African countries (Shephard, 2003; Williams

11 et al. 2004). For instance, mean total aflatoxins in $45 \%$ and $38.8 \%$ of samples of maize

12 collected from farmers in Nigeria and Benin were 200 and $105 \mu \mathrm{g} / \mathrm{kg}$, respectively

13 (Shephard, 2003). The author also reported that total aflatoxins in 15 of 16 samples of

14 Kenkey (a fermented maize product in Ghana) ranged from 6.15-196.1 $\mu \mathrm{g} / \mathrm{kg}$. Samples

15 of maize collected from households in Kenya affected by outbreaks of aflatoxicosis in

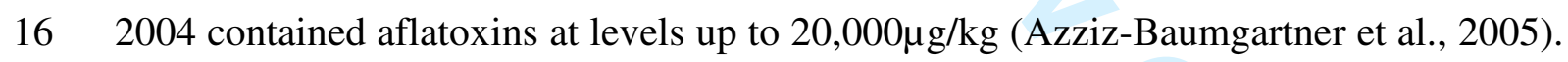

17 Also a survey of aflatoxins in food supplies in Tanzania showed high contamination of

18 these toxins in maize. In this survey, $11.2 \%$ of 472 samples of maize contained total

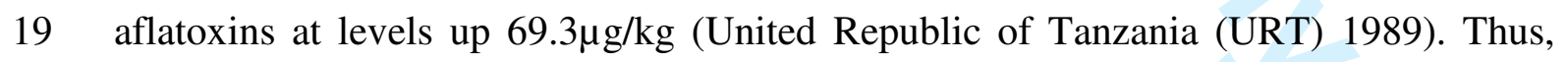

20 dietary exposure to fumonisins and aflatoxins among Tanzanians consuming maize is

21 likely. It is estimated that the annual per capita consumption of maize in Tanzania is

$22 \quad 112.5 \mathrm{~kg}$ (which is equivalent to $308 \mathrm{~g}$ per day) and the national maize utilization is

23 estimated to be three million tons per year (Food Security Department (FSD) 1996).

24 The Tanzania Food and Nutrition Centre (TFNC), a governmental institution promoting 
1 intake of nutritious food advocate daily per capita consumption of $771 \mathrm{~g}$ for non-

2 dehulled maize flour or rice and $790 \mathrm{~g}$ for dehulled maize flour for adequate energy

3 intake for an adult individual living in communities relying on these cereal products for

4 food (Tanzania Food and Nutrition Centre [TFNC] 1997).

5

6 Despite maize being a staple food for the majority of Tanzanians, no further studies

7 have been conducted to understand the magnitude of the fumonisin and aflatoxin

8 problem in Tanzanian maize. Data on occurrence and level of fumonisins and

9 aflatoxins in Tanzanian maize are needed for use in fumonisin and aflatoxin exposure

10 assessments that will provide information on the extent of fumonisin and aflatoxin

11 intake among Tanzanians and facilitate decision making for appropriate preventive

12 actions.

14 This paper reports fumonisin and aflatoxin contamination of maize and maize user

15 practices that influence their presence in food consumed in the rural areas of the main

16 maize producing regions of Tabora, Kilimanjaro, Ruvuma and Iringa in Tanzania.

18 Materials and Methods

19 Study areas and selection criteria

20 The study was conducted in the villages of Nyabula (Iringa region), Litapwasi

21 (Ruvuma region), Kikelelwa (Kilimanjaro region) and Kigwa (Tabora region) in

22 Tanzania (Figure 1). [Insert Figure 1 about here] The regions were chosen based on

23 their high maize production capacity compared to other regions of the country (FSD 
1 1996). For each region, the Regional Administrative Director suggested the leading

2 district in terms of maize production and the District Administrative officer suggested a

3 village with households relying on maize as staple food and located in an area that was

4 accessible by road was selected for the survey. In each village, 30 households who (in

5 accordance with the views of the village executive officers) could have some stock of

6 maize were selected for the survey. Therefore, a total of 120 households; 30 selected

7 from each of the villages were visited for collection of samples of stored maize and

8 data on maize sorting and user practices.

9 Climatological data of the study areas

10 Data on agro-ecological location for each region were obtained from the Ministry of

11 Agriculture, Food Security and Cooperatives, Dar es Salaam, Tanzania. Data on mean

12 temperature and relative humidity recorded over 35 years $(1971$ - 2005) for Ruvuma

13 and Iringa were obtained from the Tanzania Meteorological Agency (TMA), Dar es

14 Salaam Tanzania. These climatological data are summarized in table 1. [Insert Table I

15 about here]

16 Sampling of maize

17 In January 2006, five to six months after harvest, sampling of maize for human

18 consumption was done in all the selected households. In the households, maize was

19 found stored in shelled or unshelled form. For stores where maize was found stored in

20 unshelled form, the the stock was divided into four equal parts. Nine cobs were then

21 taken from each of the 4 parts; three from different random points on the upper, centre

22 and bottom layers of the stock. All the cobs were shelled after which the kernels were

23 mixed to obtain a homogeneous sample. In case of households where maize was found 
1 stored in shelled form (commonly in 2 to $6 \mathrm{bags}$, each of about $100 \mathrm{~kg}$ ), a probe (grain

2 trier) was used to draw incremental samples from various points of each bag. The

3 incremental samples were thoroughly mixed to compose an aggregate sample. In both

4 cases, at least one kilogram of the well mixed sample was packaged in khaki paper

5 bags, sealed and then transported to the Tanzania Food and Drugs Authority laboratory

6 in Dar es Salaam for analysis.

$8 \quad$ Collection of information on maize sorting and user practices

9 During sampling and by use of a simple questionnaire, the head of each household was

10 requested to give information on whether the maize sampled had been sorted prior to

11 storage. He was also requested to give information on whether the defective maize was

12 discarded or used as animal feed, raw material for local brews or as human food. In

13 addition he was requested to give information on type of staple food for the household

14 and whether they consumed non-dehulled maize meal (Dona) or dehulled maize meal

15 (Sembe). Dona is a widely used Swahili word for stiff porridge made from non-

16 dehulled maize meal, whereas Sembe is a Swahili word for stiff porridge made from

17 dehulled maize meal.

\section{Determination of fumonisins}

19 Fumonisin $B_{1}$ and $B_{2}$ in the maize were determined by an HPLC method based on

20 Sydenham et al. (1992) and the slight modifications made by Samapundo et al. (2006).

22 Extraction and clean-up. 
1 Fumonisins were extracted overnight from $15 \mathrm{~g}$ of a finely ground portion of the maize

2 with $40 \mathrm{ml}$ of methanol: water $(3: 1, \mathrm{v}: \mathrm{v})$ in $100 \mathrm{ml}$ glass bottles fitted on a horizontal

3 laboratory shaker. The slurry was filtered through Whatman No 1 filter paper and the

4 bottle rinsed with $10 \mathrm{ml}$ of the mix of methanol and water. The $\mathrm{pH}$ of the filtrate was

5 measured and values were always within the normal $\mathrm{pH}$ range for maize based material

6 (between 5.8 and 6.5).

7

8 A $10 \mathrm{ml}$ aliquot of the filtered extract was applied to a strong anion exchange (SAX)

9 cartridge (Varian, Bond-Elut LRC, 500 mg, Varian Belgium NV/SA, Belgium ) fitted

10 to a solid phase extraction manifold (Alltech, 24- Port SPE Vacuum Manifold System,

11 ALLTECH Associates Inc, Lokeren, Belgium). Before applying the extract, the SAX

12 cartridge was conditioned with $5 \mathrm{ml}$ of methanol, followed by $5 \mathrm{ml}$ of a methanol-water

$13 \operatorname{mix}(3: 1, \mathrm{v}: \mathrm{v})$. After application of the extract, the SAX cartridge was then washed

14 with $8 \mathrm{ml}$ of the methanol-water mix (3:1, v: v), followed by $3 \mathrm{ml}$ of methanol. The

15 fumonisins were eluted from the cartridge with $10 \mathrm{ml}$ of $1 \%(\mathrm{v}$ : v) glacial acetic acid in

16 methanol. The eluate was collected and evaporated to dryness at $60^{\circ} \mathrm{C}$ under a gentle

17 stream of nitrogen using a Nitrogen Evaporator (PIERCE model 18780, Reacti-Vap)

18 coupled with a dry bath (PIERCE Reacti-Therm), both supplied by Rockford, Illinois,

19 USA.

20 HPLC analysis.

21 The dry fumonisins were dissolved in $200 \mu$ l of methanol. The solution was thoroughly

22 mixed with $200 \mu \mathrm{l}$ of a derivatizing reagent prepared by dissolving $40 \mathrm{mg}$ of ortho-

23 phthaldehyde in a mixture of $1 \mathrm{ml}$ of methanol, $5 \mathrm{ml}$ of $0.1 \mathrm{M}$ sodium tetraborate and

$2450 \mu 1$ of $\beta$-mercaptoethanol. Twenty $\mu 1$ of the mixture was injected within 4 min into 
1 the HPLC for analysis using a reversed-phase HPLC fluorescence detection system. A

2 Waters HPLC system consisting of a Waters 600 pump and controller was used. The

3 system was connected to a Shimadzu SIL-10ADvp auto injector. Chromatographic

4 separations were performed on a Discovery C8 column $(100 \mathrm{X} 4.6 \mathrm{~mm}, 5 \mu \mathrm{m}$;

5 SUPELCO, Supelco Park, Bellefonte, PA, USA). Methanol - $0.1 \mathrm{M}$ sodium

6 dihydrogen phosphate (75:25, v:v) mixture adjusted to $\mathrm{pH} 3.35$ with orthophosphoric

7 acid was used as mobile phase. The flow rate of the mobile phase was $1 \mathrm{ml} / \mathrm{min}$.

8 Fluorescence of the fumonisin OPA derivatives was detected at wavelengths of $335 \mathrm{~nm}$

9 (excitation) and 400nm (emission) using a Shimadzu RF-10AXL fluorescence detector

10 and recorded with a Shimadzu C-R3A Chromatopac integrator.

12 The limit of detection of the analytical method, defined as the mean value of the blank

13 readings plus three standard deviations, was $53 \mu \mathrm{g} / \mathrm{kg}$ for fumonisin $\mathrm{B}_{1}$ and $47 \mu \mathrm{g} / \mathrm{kg}$ for

14 fumonisin $B_{2}$. To evaluate suitability of the method blank samples of maize were

15 spiked with $\mathrm{FB}_{1}$ and $\mathrm{FB}_{2}$ each at $100,200,300,400$ and $500 \mu \mathrm{g} / \mathrm{kg}$. Average recovery

16 values were $106 \%$ [five samples, relative standard deviation (RSD) of $16.6 \%$ ] and $92 \%$

17 (five samples; RSD of $15.3 \%$ ) for $\mathrm{FB}_{1}$ and $\mathrm{FB}_{2}$ respectively. The results were corrected

18 for recovery.

\section{Determination of aflatoxins}

20 Aflatoxin $B_{1}, B_{2}, G_{1}$ and $G_{2}$ were determined in the maize in accordance with the

21 method described by Stroka et al. (2000) and slight modification made by Samapundo 22 et al. (2007). 
1 Extraction and clean-up procedure. Briefly, aflatoxins were extracted from $20 \mathrm{~g}$ of a

2 finely ground portion of the maize with $40 \mathrm{ml}$ of an acetonitrile-water solution $(3: 1, \mathrm{~V}$ :

$3 \mathrm{~V}$ ) in a $100 \mathrm{ml}$ glass bottle fitted on a horizontal laboratory shaker. The suspension was

4 filtered through two layers of Whatman No 1 filter paper and the bottle rinsed with 10

$5 \mathrm{ml}$ of the acetonitrile-water solution. Four $\mathrm{ml}$ of the extract were adjusted to $\mathrm{pH} 7$ by

$60.1 \mathrm{M} \mathrm{NaOH}$ solutions and then diluted by at least $36 \mathrm{ml}$ of phosphate buffer saline

7 solution ( $\mathrm{pH} 7.4, \mathrm{NaCl} 0.15 \mathrm{M}$ ). The diluted extract was then passed through AflaStar

8 immunoaffinity column (IAC) (Romer Lab, Coring System Diagnostix GmbH,

9 Gernsheim, Germany) fitted to a solid phase extraction manifold (24- Port SPE

10 Vacuum Manifold System, ALLTECH Associates Inc, Lokeren, Belgium) and allowed

11 to flow through without application of vacuum. Twenty five $\mathrm{ml}$ of water was then used

12 to rinse the container that held the extracts before passage through the column.

13 Aflatoxins were eluted by use of $3 \mathrm{ml}$ of methanol applied as $0.5 \mathrm{ml}$ aliquots which

14 were held in the bed for about 3 minutes. A slight vacuum was applied to remove any

15 liquid remaining in the bed.

16 HPLC analysis.

17 Twenty $\mu 1$ of the eluate was injected to the HPLC for analysis using a reversed-phase

18 HPLC fluorescence detection system. No derivatisation of the aflatoxins was performed

19 (Samapundo et al., 2007). A Waters HPLC system consisting of a Waters 600 pump

20 and controller was used. The system was connected to a Shimadzu SIL-10ADvp auto

21 injector, a Shimadzu RF-10AXL florescence detector and Shimadzu C-R3A

22 chromatopac integrator. Chromatographic separations were performed on a Bondapak

23 ODS column $(250 \times 4.6 \mathrm{~mm}, 5 \mu \mathrm{m}$ pore size $)$. A methanol-water mixture (1:1, v:v) was

24 used as mobile phase. Flow rate of the mobile phase was set at $0.7 \mathrm{ml} / \mathrm{min}$. Fluorescence 
1 of the aflatoxins was recorded at wavelengths of $360 \mathrm{~nm}$ (excitation) and 440nm

2 (emission).

4 The limit of detection of the analytical method (also defined as the mean value of the

5 blank readings plus three standard deviations) was $0.6 \mu \mathrm{g} / \mathrm{kg}$ for each of $\mathrm{AFB}_{1}$ and

$6 \mathrm{AFG}_{1}$ and $0.07 \mu \mathrm{g} / \mathrm{kg}$ for each of $\mathrm{AFB}_{2}$ and $\mathrm{AFG}_{2}$. To assess the repeatability of the

7 method, $\mathrm{AFB}_{1}$ and $\mathrm{AFG}_{1}$ were spiked into blank maize samples, each at $0.76,3.81$ and

$86.85 \mu \mathrm{g} / \mathrm{kg}$ and recovered, on average, by $89 \%$ (three samples; RSD of $15.7 \%$ ) and

$9107 \%$ (three samples; RSD of $19.8 \%$ ), respectively. The blank maize samples were

10 also spiked with $\mathrm{AFB}_{2}$ and $\mathrm{AFG}_{2}$, each at $0.56,1.31$ and $1.675 \mu \mathrm{g} / \mathrm{kg}$ which, on average,

11 were recovered by $87 \%$. The RSD value for three maize samples spiked with the $\mathrm{AFB}_{2}$

12 was $14.3 \%$ and $\mathrm{AFG}_{2}, 22.9 \%$. The results were corrected for recovery.

14 Determination of percentage defective kernels

15 The samples of maize were subjected to examination of percentage defective (broken,

16 wrinkled, visibly mouldy, rotten or discoloured) kernels. Two hundred kernels were

17 randomly taken from each sample and the defective kernels counted out and expressed

18 as percentage of the 200 kernels.

20 Statistical analysis of data

21 The statistical package used was Stata version 9 (Stata 9.0; Statacorp, Texas, USA).

22 Correlation analysis was used to determine relationship between percentage defective

23 kernels and fumonisin or aflatoxin levels in the samples. Means were compared by 24 analysis of variance (ANOVA). 
2 Results and discussion

$3 \quad$ Sorting and use of damaged and mouldy maize

4 Table II shows the number of households who sorted maize before storage and the

5 number of these households who discarded the defective maize and who used it as food,

6 raw material for local brews or animal feed. Out of the 120 households, 110 sorted

7 maize prior to storage separating insect damaged and mouldy maize from the main

8 harvest.

9

10 [Insert Table II about here]

11

12 However, 50 out of the 110 households still admitted to consuming the damaged or

13 mouldy maize. The number of households (24 out of 30) who admitted that they

14 consume damaged or mouldy maize as food in Tabora was higher compared to the

15 number in Kilimanjaro (12 out of 30), Iringa (8 out of 30) or Ruvuma (6 out of 30).

16 The finding that people in Tanzania consumed sorted damaged or mouldy maize is in

17 contrast to a recent report that in the former Transkei region of South Africa, almost all

18 (161) households who participated in a study of exposure to fumonisins in maize used

19 the sorted mouldy maize as animal feed or raw material for beer (Shephard et al., 2007).

20 Consumption of mouldy maize either as direct food or via local brews is indicative of

21 the magnitude of the problem of food insecurity in the rural places (Sydenham et al.

22 1990). In this study relatively fewer households, 30 used the damaged or mouldy maize

23 as animal feed and 19 as raw material for beer. Only 21 of the 110 households said they 
1 discard the damaged or mouldy maize. According to the participants to our study,

2 defective maize was separated from good quality maize and used within the first two

3 months after harvest in order to avoid further deterioration which is normally

4 experienced in unsorted maize stored for prolonged time.

5

6 The observation that people consumed damaged and mouldy maize is of great

7 importance as mouldy maize contains more fumonisins and aflatoxins compared to

8 visibly good quality maize. Studying the fate of fumonisins and aflatoxins during

9 processing of maize to food products in Benin, Fandohan et al. (2005) found that

10 sorting and winnowing reduced mean aflatoxin level in maize from $6.57 \mu \mathrm{g} / \mathrm{kg}$ to 2.67

$11 \mu \mathrm{g} / \mathrm{kg}$ and mean fumonisin level from $4800 \mu \mathrm{g} / \mathrm{kg}$ to $1500 \mu \mathrm{g} / \mathrm{kg}$. According to the

12 researchers the fumonisins were significantly recovered in the discarded mouldy and

13 damaged kernels. High levels of fumonisins in mouldy maize have been reported by

14 other researchers in Ghana $(52,670 \mu \mathrm{g} / \mathrm{kg}$ ) (Kpodo et al. 1996) and South Africa (49

$15900 \mu \mathrm{g} / \mathrm{kg}$ ) (Sydenham et al. 1990) Thus, in order to prevent use of mouldy maize as

16 food, farmers should be educated and made to realise the presence of high levels of

17 mycotoxins in the mouldy fraction as well as health effects of the toxins.

\section{Consumption of Dona}

19 The participants to this study said that they consume Dona or Sembe as their staple

20 food. From the 120 households, 36 respondents said they consume Dona. These

21 respondents represent $90 \%$ of households in Kilimanjaro and $27 \%$ in Tabora.

22 Households in Iringa and Ruvuma consumed Sembe. People consuming Dona are at a

23 higher risk of exposure to mycotoxins than those consuming Sembe because Sembe is

24 made from dehulled maize. Dehulling reduces the mycotoxin content in maize by 
1 removing the more contaminated pericarp and germ (Fandohan et al. 2005, Miller

2 1995). Fandohan et al.(2005) reported that in preparation of maize food products in

3 Benin, about $34 \%$ of aflatoxin in the maize was removed with the discarded hulls and

4 embryo and that the mean fumonisin content decreased from $2890 \mu \mathrm{g} / \mathrm{kg}$ (in the raw

5 maize) to $1350 \mu \mathrm{g} / \mathrm{kg}$ (in the de-hulled maize). It is worth noting that, communities

6 consuming Dona maize meal as staple food may use it for preparation of

7 complementary foods for their children (Shephard et al. 1996). Children consuming

8 Dona based foods might be at an even higher risk of exposure to mycotoxin given that

9 their food needs per kilogram body weight per day are higher than in adults.

\section{Fumonisin contamination}

11 Fifty two percent of the 120 samples were contaminated with $\mathrm{FB}_{1}$ at levels up to 6125

$12 \mu \mathrm{g} / \mathrm{kg}$ (median, $206 \mu \mathrm{g} / \mathrm{kg}$ ). $\mathrm{FB}_{2}$ were determined in $36 \%$ of the samples at levels up to $134923 \mu \mathrm{g} / \mathrm{kg}$ (median, $239 \mu \mathrm{g} / \mathrm{kg}$ ). Total fumonisins $\left(\mathrm{FB}_{1}+\mathrm{FB}_{2}\right)$ in the contaminated 14 samples were recorded for $52 \%$ of the samples, at levels ranging from $61-11,048$

$15 \mu \mathrm{g} / \mathrm{kg}$ (median, $363 \mu \mathrm{g} / \mathrm{kg}$ ). Levels determined by this study compare very well with

16 levels determined by other studies which analysed home-grown maize in rural areas of

17 Africa. Gamanya and Sibanda (2001) reported $\mathrm{FB}_{1}$ levels ranging from 4000-8000

$18 \mu \mathrm{g} / \mathrm{kg}$ in samples of maize from villages in Zimbabwe. Sydenham et al. (1990) and

19 recently Shephard et al (2007) reported similar fumonisin levels in good quality home

20 grown-maize from the high oesophageal area of the former Transkei region of South

21 Africa (maximum levels of $7900 \mu \mathrm{g} / \mathrm{kg}$ for $\mathrm{FB}_{1}, 3770 \mu \mathrm{g} / \mathrm{kg}$ for $\mathrm{FB}_{2}$ and $10,140 \mu \mathrm{g} / \mathrm{kg}$

22 for total fumonisins ). A similar maximum level of $12000 \mu \mathrm{g} / \mathrm{kg}$ was reported by

23 Fandohan et al. (2006) for the 1999-2000 harvest of maize in Benin. However, the

24 highest level of $6125 \mu \mathrm{g} / \mathrm{kg}$ for $\mathrm{FB}_{1}$ and $11,048 \mu \mathrm{g} / \mathrm{kg}$ for total fumonisin determined 
1 by this study are higher than the respective contaminations of $165 \mu \mathrm{g} / \mathrm{kg}$ and $225 \mu \mathrm{g} / \mathrm{kg}$

2 reported previously by Doko et al. (1996) for samples of maize from Tanzania. The

3 same authors reported total fumonisin levels of $370 \mu \mathrm{g} / \mathrm{kg}$ for maize from Botswana,

$4 \quad 135 \mu \mathrm{g} / \mathrm{kg}$ for maize from Malawi and $2735 \mu \mathrm{g} / \mathrm{kg}$ for maize from Zimbabwe. A

5 relatively lower maximum level of $4222 \mu \mathrm{g} / \mathrm{kg}$ for total fumonisins was also reported

6 by Kpodo et al. (2000) for maize in Ghana. As opposed to the current study, the other

7 studies analysed maize from market outlets which is known to contain low levels of

8 contamination compared to home stored maize (Shephard et al., 1996). Just like found

9 by other researchers (Kpodo et al. 2000, Doko et al. 1996), $\mathrm{FB}_{1}$ was more prevalent and

10 present at higher levels than $\mathrm{FB}_{2}$. On average, $\mathrm{FB}_{2}$ corresponded to $31 \%$ of the total

11 fumonisins recorded in this study.

13 The occurrence and level of mycotoxins in a country vary from one geographical

14 region to another (Fandohan et al. 2006, Hell at al. 2000). [Insert Table III about here]

15 Table III shows occurrence and distribution of the fumonisin contaminated samples at

16 different levels of contamination in the different regions. Fumonisins were widespread

17 (70\%) in Tabora compared to Ruvuma (50), Kilimanjaro (44\%) and Iringa (43).

18 During the maize production season of 2005, Tanzania experienced drought which

19 might have influenced contamination of maize with fumonisins. Drought stress

20 condition might have been severe in Tabora compared to the other regions resulting in

21 more favourable conditions for fungal attack and fumonisin formation in maize in that

22 region (Miller 2001). Tabora is generally warm and one of the two regions that

23 experience lower rainfall of $800-1000 \mathrm{~mm} /$ year compared to the other regions which

24 receive $900-2000 \mathrm{~mm} /$ year. 
2 Despite Kilimanjaro being less prone to drought, relatively higher levels of fumonisins

3 were observed in samples from this region. Seven percent of samples from Kilimanjaro

4 contained fumonisin levels above $4000 \mu \mathrm{g} / \mathrm{kg}$, the MTL in whole maize products in the

5 US (Soriano and Dragacci 2004). Farmers in Kilimanjaro region harvested maize from

6 May to July, a period which coincided with the main rain period of March to June

7 (Table I). Under rainfall condition, mature maize experiences prolonged periods of high

8 water content that may favour mould growth and mycotoxin formation. Gamanya and

9 Sibanda (2001) reported that $\mathrm{FB}_{1}$ concentration in food in Zimbabwe decreased from

10 regions with high rainfall and annual moderate temperature to low rainfall regions.

12 Since Tanzania (just like most other African countries) does not have a MTL for

13 fumonisins, contamination results obtained in this study were compared with the MTL

14 of $1000 \mu \mathrm{g} / \mathrm{kg}$ set for fumonisins in maize for human consumption in other countries

15 including the European Union (van Egmond et al. 2007) and Switzerland (Soriano and

16 Dragacci 2004). It was observed that $15 \%$ of the 120 samples (at least $10 \%$ of samples

17 from each of Kilimanjaro, Tabora, Iringa and Ruvuma) exceeded this limit (Table III).

18 Shephard et al. (1996) indicated that the MTL of fumonisins set in developed countries

19 were based on low maize consumption (as low as $8.8 \mathrm{~g}$ of maize/person/day).This

20 means that with the high per capita maize consumption of $308 \mathrm{~g}$ of maize/person/day

21 in Tanzania (FSD 1996) an appropriate MTL would be set far below the $1000 \mu \mathrm{g} / \mathrm{kg}$.

22 In this case, more than $15 \%$ of the samples would exceed the appropriate MTL if it

23 existed in Tanzania. 
1 Aflatoxin contamination.

2 The $\mathrm{AFB}_{1}$ was determined in $12 \%$ of the samples at levels ranging from $5-90 \mu \mathrm{g} / \mathrm{kg}$

3 (median, $38 \mu \mathrm{g} / \mathrm{kg}$ ). $\mathrm{AFG}_{1}$ was determined in $9 \%$ of the samples at levels ranging from

$44-89 \mu \mathrm{g} / \mathrm{kg}$ (median, $29 \mu \mathrm{g} / \mathrm{kg}$ ), $\mathrm{AFB}_{2}$ in $8 \%$ of the samples at a range from $1-20$

$5 \mu \mathrm{g} / \mathrm{kg}$ (median, $6 \mu \mathrm{g} / \mathrm{kg}$ ) and $\mathrm{AFG}_{2}$ in $10 \%$ of the samples at levels from $1-17 \mu \mathrm{g} / \mathrm{kg}$

6 (median, $3 \mu \mathrm{g} / \mathrm{kg}$ ). Total aflatoxins $\left(\mathrm{AFB}_{1}+\mathrm{AFB}_{2}+\mathrm{AFG}_{1}+\mathrm{AFG}_{2}\right)$ were recorded for

$7 \quad 18 \%$ of the samples at levels ranging from $1-158 \mu \mathrm{g} / \mathrm{kg}$ (median, $24 \mu \mathrm{g} / \mathrm{kg}$ ). The study

8 confirms a previous report by the United Republic of Tanzania [URT] (1989), that

9 Tanzanian maize is contaminated with unacceptable levels of aflatoxins.

11 Table IV shows distribution of aflatoxins contaminated samples in the regions.

12 Occurrence $(\%)$ of aflatoxin contaminated maize was significantly higher in Tabora

13 compared to the other regions $(\mathrm{P}<0.016)$. Thirty seven percent of samples from Tabora

14 were contaminated with $\mathrm{AFB}_{1}$ or total fumonisins. Aflatoxins were determined in $20 \%$

15 of the samples from Kilimajaro. Only a small fraction (7\%) of samples from each of

16 Iringa and Ruvuma were contaminated with aflatoxins. [Insert Table IV about here]

17 As explained for the case of high occurrence of fumonisin contamination, the warm and

18 dry climatic conditions prevailing in Tabora region could be attributed to these 19 observations.

21 Tanzania regulates maximum limits of $\mathrm{AFB}_{1}$ and total aflatoxins in food at $5 \mu \mathrm{g} / \mathrm{kg}$ and

$2210 \mu \mathrm{g} / \mathrm{kg}$ respectively (Tanzania Bureau of Standards [TBS] 2004). In general $11 \%$ and

$2312 \%$ of the 120 samples were contaminated with $\mathrm{AFB}_{1}$ and total aflatoxins at levels

24 above the Tanzania MTL of $5 \mu \mathrm{g} / \mathrm{kg}$ and $10 \mu \mathrm{g} / \mathrm{kg}$, respectively. Samples from Tabora 
1 accounted for $77 \%$ and $64 \%$ of the samples exceeding the MTL of $5 \mu \mathrm{g} / \mathrm{kg}\left(\mathrm{AFB}_{1}\right)$ and

$210 \mu \mathrm{g} / \mathrm{kg}$ (total aflatoxins) respectively. With the exception of one sample, all

$3 \quad \mathrm{AFB}_{1}$ contaminated samples exceeded the limit of $5 \mu \mathrm{g} / \mathrm{kg}$.

4 Co-occurrence of aflatoxins with fumonisins

5 Fumonisins and aflatoxins co-occurred in 12 out of the 120 samples; 7 from Tabora, 4

6 from Kilimanjaro and one from Ruvuma. Total fumonisin levels in the co-contaminated

7 samples ranged from $111-11,048 \mu \mathrm{g} / \mathrm{kg}$ (mean, $2157 \mu \mathrm{g} / \mathrm{kg}$ ) and aflatoxins from 1-

$8151 \mu \mathrm{g} / \mathrm{kg}$, (mean, $44 \mu \mathrm{g} / \mathrm{kg}$ ). Fifty eight percent of the 12 samples were co-

9 contaminated with fumonisins and aflatoxins at levels above the respective MLs of

$101000 \mu \mathrm{g} / \mathrm{kg}$ and $10 \mu \mathrm{g} / \mathrm{kg}$. Co-occurrence of aflatoxins with fumonisins has also been

11 reported for maize in Ghana (Kpodo et al. 2000) and in Benin (Hell et al. 2000b).

12 Important to note as well is that presence of fumonisins and aflatoxins in Tanzanian

13 maize is indicative of the presence of Fusarium and Aspergillus moulds in the maize.

14 Fusarium and Aspergillus genera of moulds exist in various species that produce other

15 forms of mycotoxins including nivalenol (NIV), Zearalenone (ZEA), Deoxynivalenol

16 (DON) (Sydenham et al. 1990) and Ochratoxin A (Miller 1995, WHO 2002) in food.

17 Zearalenone occurred in two out of 9 samples of maize from Tanzanian which were

18 analysed by Doko et al. (1996) and in one of those samples the toxin co-occurred with

19 fumonisins. This observation is in accordance with the views of other scientists that

20 people consuming maize are at a high risk of exposure to multiple mycotoxins

21 (Shephard et al. 1996, Miller 1995, Sydenham et al. 1990, Kpodo et al. 2000). Thus

22 efforts need be taken to study Fusarium and Aspergillus species contaminating maize

23 in Tanzania with a view to understand their geographical distribution and potential to 
1 produce toxins in food. The information will be useful in formulation of strategies that

2 can target more than one type of mycotoxins.

3 Relationship between percent defective kernels and fumonisins or aflatoxins

4 All the samples contained defective kernels irrespective of whether they were drawn

5 from maize that had been sorted before storage or not. Eighty eight percent of the

6 samples contained defective kernels at levels above 7\%; the ML recommended by the

7 Codex Alimentarius Commission for maize or corn (Codex Alimentarius Commission

8 (CAC) 1995). All the samples (100\%) from Kilimanjaro, 93\% from Tabora, $87 \%$ from

9 Iringa and $70 \%$ from Ruvuma exceeded the ML of $7 \%$. The means of percent defective

10 kernels were not significantly different among the regions $(\mathrm{P}>0.3644)$. [Insert Table V

11 about here]

13 Table V shows a general increase in fumonisin levels from low percentage defective

14 samples to high percentage defective samples. For all the samples containing less than

$157 \%$ defective kernels, fumonisin levels were lower than MTL of $1000 \mu \mathrm{g} / \mathrm{kg}$. The

16 maximum fumonisin level increased from $685 \mu \mathrm{g} / \mathrm{kg}$ (defective range $\leq 7 \%$ ), through

$175989 \mu \mathrm{g} / \mathrm{kg}$ (defective range, $7<30$ ) to $11048 \mu \mathrm{g} / \mathrm{kg}$ (defective range, $\geq 30 \%$ ). Though

18 weak, there was positive correlation between fumonisin contamination and extent of

19 defective kernels in the sample $(\mathrm{r}=0.39)$. Similar observations were made by Charmly

20 (1995) who reported that incidence of defective kernels in maize may be used to

21 predict the likelihood of fumonisin contamination in a maize stock. Nonetheless,

22 despite the presence of more than $7 \%$ defective kernels in $100 \%$ of the samples from

23 Kilimanjaro, only $44 \%$ of samples from that region were contaminated with detectable 
1 fumonisins. This observation suggests that more studies are needed to investigate

2 effectiveness of sorting as a means for reduction of fumonisins in maize.

3

4 Aflatoxins were not detected in any of the samples that contained less than $7 \%$

5 defective kernels (Table 7). This finding is in agreement with reports by other

6 researchers who observed a positive relationship between aflatoxins and insect damage

7 in maize in Benin (Hell et al. 2000a, Setamou et al. 1998).

\section{Conclusions}

10 This study confirms that fumonisins and aflatoxins are widespread contaminants of

11 maize intended for human consumption in Tanzania. It shows that populations in the

12 rural areas of Tanzania are at a risk of exposure to unacceptably high levels of

13 fumonisins and aflatoxins. Based on their consumption of Dona and the high fumonisin

14 contamination determined in samples from the Kilimanjaro region, people in that

15 region are at a relatively higher risk of exposure to fumonisins. Children consuming

16 Dona based complementary foods might be at an even higher risk of exposure to these

17 toxins. The findings of this study should trigger further research that will generate data

18 on the fumonisin and aflatoxins exposure among Tanzanians (children inclusive). The

19 exposure data and information on the extent to which dehulling performed by

20 householders actually reduces mycotoxin contamination of maize are needed to provide

21 further scientific basis for strengthening mycotoxin control strategies in this and other

22 developing countries.

23 
1 Despite the existence of regulatory limits for $\mathrm{AFB}_{1}$ and total aflatoxins in maize for

2 human consumption in Tanzania, a substantial fraction (11\%) of maize in rural places

3 contained unacceptable levels of these toxins. The observation is in agreement with

4 views of other authors (Shepahrd et al. 1996; Williams et al., 2004) that enforcement

5 of MTLs for mycotoxins in foods is a measure that is not protective for people in rural

6 settings. Rural populations consuming own grown crops would eat their produce

7 unchecked for safety limits. Therefore appropriate technologies for minimizing

8 fumonisins in maize during farming, transport, storage and preparation for use need to

9 be adopted by farmers and households in the rural places. These could include adoption

10 of fungal resistant varieties and good agricultural and handling practices such as use of

11 fertilizers in growing maize and sorting to remove mouldy maize prior to storage and

12 use. In view of this, agricultural extension officers advising farmers on good

13 agricultural practices should be provided with a mycotoxin control package of good

14 agricultural practices that they should advocate to farmers in the rural areas for

15 adoption. Other measures could include campaigns to sensitize the public on effects of

16 mycotoxins in human health and their impact on the economy. As a complementary

17 strategy mothers should be advised to exercise care in selection ingredients for

18 complementary foods and when a possibility exist, maize should be replaced with other

19 least contaminated cereals such as sorghum and millets (Munimbazi and Bullerman

20 1996). Maize containing less than $7 \%$ defective kernels contained relatively low

21 contamination of fumonisins and aflatoxins, suggesting that proper sorting of maize

22 prior to consumption is an important measure for the reduction of fumonisin content in

23 maize. However, more studies need be conducted to investigate the extent to which 
1 sorting as practised by householders themselves can be relied on as a measure for

2 reduction of mycotoxin contamination in maize in Tanzania.

3

4 The ongoing efforts to discover fungi resistant crops and decontamination techniques

5 for fumonisins in food will probably provide a long lasting solution to the problem of

6 fumonisin contamination of the staple food for the subsistence-farming systems in the

7 developing countries. 


\section{Acknowledgement}

3 The authors thank the International Foundation for Science (IFS), the Nutrition Third

4 World (NTW) and the Belgium Technical Cooperation (BTC) for funding this study.

5 The authors are also grateful to the food consumption and mycotoxin research clusters

6 of the NutriFoodChem research group (Ghent University) for their contribution in

7 designing the study. Also, the authors would like to thank the managements for the

8 TFDA and TFNC; and the administrative authorities for Iringa, Tabora, Ruvuma and

9 Kilimanajaro regions for their support during the field work. Also appreciation goes to

10 Juma Amiri, Anita Bitegeko, Gladness Kanza and other staff who helped in analysis of 11 the samples.

\section{References}

14 Azziz-Baumgartner E, Lindblade, K, Gieseker K, Rogers HS, Kieszak S, Njapau H, 15 Schleicher R, McCoy LF, Misore A, DeCock K, Rubin C, Slutsker L, the 16 Afalatoxin Investigatve Group.2005. Case-control study of an acute 17 aflatoxicosis outbreak in Kenya. Environmental Health Perspectives 113:17791783.

19 Charmley LL, Prelusky DB. 1995. Decontamination of Fusarium mycotoxins. 20 Applied and Environmental Microbiology 1:421-435.

21 Chu FS, Li GY. 1994. Simultaneous occurrence of fumonisins B1 and other mycotoxins in moldy corn collected from the people's republic of China in regions with high incidences of eosophageal cancer. Applied and Environmental Microbiology 60-847-852. 
1 CAC. 1995. Codex Standard for Maize. Codex Stan 153-1985 (Rev.1-1995). p 6. Available :http://www.codexalimentarius.net/search/advancedsearch.do via the INTERNET. Accessed 2007 May 11.

Doko MB, Canet C, Brown N, Sydenham EW, Mpuchane S, Siame BA. 1996. Natural co-occurrence of fumonisins and zearalenone in cereals and cerealbased foods from Eastern and Southern Africa. Journal of Agricultural and Food Chemistry 44:3240-3243.

Doko MB, Visconti A. 1994. Occurrence of fumonisin-B(1) and fumonisin-B(2) in corn and corn-based human foodstuffs in Italy. Food Additives and Contaminants 11:433-439.

Fandohan P, Gnonlonfin B, Hell K, Marasas WFO, Wingfield MJ. 2006. Impact of indigenous storage systems and insect infestation on the contamination of maize with fumonisins, African Journal of Biotechnology 5:546-552.

Fandohan P, Zoumenou D, Hounhouigan D J, Marasas WFO, Wingfield MJ, Hell K. 2005. Fate of aflatoxins and fumonisins during the processing of maize into food products in Benin, International Journal of Food Microbiology 98:249-259. practices on aflatoxin contamination in maize in four agroecological zones of Benin, west Africa. Journal of Stored Products Research 36:365-382. 
Hell K, Cardwell KF, Setamou M, Schulthess F. 2000b. Influence of insect infestation on aflatoxin contamination of stored maize in four agroecological regions in Benin, African Entomology 8: 169-177.

International Agency for Research on Cancer (IARC). 2002. Fumonisin B1. Some

Miller JD. 1995. Fungi and mycotoxins in grain - Implications for stored-products. 
1 Munimbazi, C., Bullerman, LB., 1996. Molds and mycotoxins in foods from Burundi. Journal of Food Protection. 59: 869-875.

Rheeder JP, Marasas WFO, Thiel PG, Sydenham EW, Shephard GS, van Schalkwyk DJ. 1992. Fusarium-Moniliforme and fumonisins in corn in relation to human esophageal cancer in Transkei. Phytopathology 82:353-357

Rheeder J P, Sydenham EW, Marasas WFO, Thiel PG, Shephard GS, Schlechter M, Stockenstrom S, Cronje DW, Viljoen JH. 1995. Fungal Infestation and Mycotoxin contamination of South-African commercial maize harvested in 1989 and 1990. South African Journal of Sciences. 91-127-131.

10 Samapundo S, De Meulenaer B, De Muer N, Debevere J, Devlieghere F. 2006. Influence of experimental parameters on the fluorescence response and recovery of the high-performance liquid chromatography analysis of fumonisin B-1. Journal of Chromatography A 1109:312-316.

Samapundo S, De Meulenaer B, Osei-Nimoh D, Lamboni Y et al. 2007. Can phenolic compounds be used for the protection of corn from fungal invasion and mycotoxin contamination during storage? Food Microbiology 24:465-473.

Setamou M, Cardwell K F, Schulthess F. Hell K. 1998. Effect of insect damage to maize ears, with special reference to Mussidia nigrivenella (Lepidoptera : Pyralidae), on Aspergillus flavus (Deuteromycetes : Monoliales) infection and aflatoxin production in maize before harvest in the Republic of Benin. Journal of Economic Entomology 91:433-438. Journal of Toxicology, Toxins Reviews. 22: 267-286. 
Shephard, GS, Marasas WFO, Burger HM, Somdyala NIM, Rheeder JP, Van Der Westhuizen L, Gatyeni P, Van Schalkwyk DJ. 2007. Exposure assessment for

$$
\text { Contaminants 24:621-629. }
$$

Shephard GS, Thiel PG, Stockenstrom S, Sydenham EW. 1996. Worldwide survey of fumonisin contamination of corn and corn-based products. Journal of AOAC International 79:671-687.

Soriano JM, Dragacci S. 2004. Intake, decontamination and legislation of fumonisins in foods. Food Research International 37:367-374

Stroka J, Anklam E, Jorissen U, Gilbert J. 2000. Immunoaffinity column cleanup with liquid chromatography using post-column bromination for determination of aflatoxins in peanut butter, pistachio paste, fig paste, and paprika powder: Collaborative study. Journal of AOAC International 83-320-340.

Sydenham EW, Thiel PG, Marasas WFO, Shephard GS, Van Shalkwyk DJ, Koch KR. 1990. Natural occurrence of some Fusarium mycotoxins in corn from low and high oesophageal cancer prevalence area of the Transkai, Southern Africa. Journal of Agricultural and Food Chemistry 38-1900-1903.

Sydenham EW, Shephard GS, Thiel PG.1992. Liquid-chromatographic determination of fumonisin-B1, fumonisin-B2, and fumonisin-B3 in foods and feeds. Journal of Aoac International 1992, 75, 313-318.

TBS. 2004. Rice Specification. TZS 592. Tanzania Bureau of Standards, Dar es Salaam, Tanzania.

TFNC. 1997. Matumizi ya kadi ya uhakika wa chakula katika kaya. Mwongozo kwa wafanyakazi wa ugani., TFNC, Dar es Salaam, Tanzania. 
1 URT. 1989. Strategies and recommendations for mycotoxin control in Tanzania. Report prepared for the Government of Tanzania by FAO/UNEP/USSR/Tanzania Project FP/7101/86/03. Centre for International Projects. USSR State Committee for Environment Protection, Moscow. van Egmond, HP.,Schothorst, R.C., Jonker, MA 2007. Regulations relating to mycotoxins in food. Analytical and Bioanalytical Chemistry 389: 147-157.

Wang H, Wei H, Ma J, Luo X. 2000. The fumonisin B1 content in corn from North China, a high-risk area of oesophageal cancer. Journal of Environmental Pathology Toxicology and Oncology 19-139-141;

WHO. 2002. Evaluation of certain mycotoxins in food. Fifty-sixth report of the Joint FAO/WHO Expert Committee on Food Additives, WHO Technical Report Series 906, Geneva, Switzerland.

Williams JH, Phillips TD, Jolly PE, Stiles JK, Jolly CM, Aggarwal D. 2004. Human aflatoxicosis in developing countries: a review of toxicology, exposure, potential health consequences, and interventions. American Journal of Clinical Nutrition 80:1106-1122. 


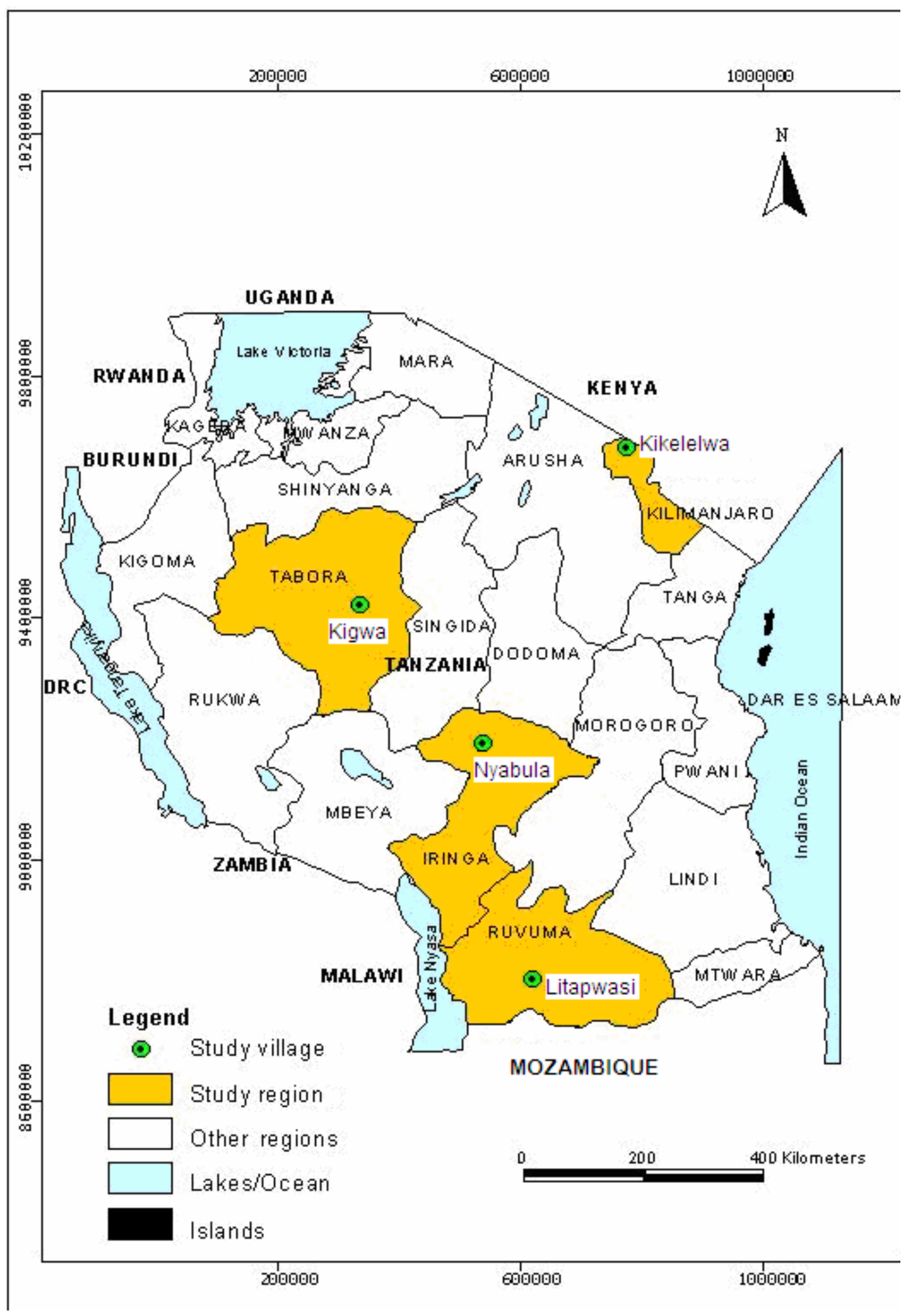

1. Figure 1: Map of Tanzania showing study sites 
1 Table I: Climatological data for Tabora, Ruvuma, Kilimanjaro and Iringa regions of Tanzania

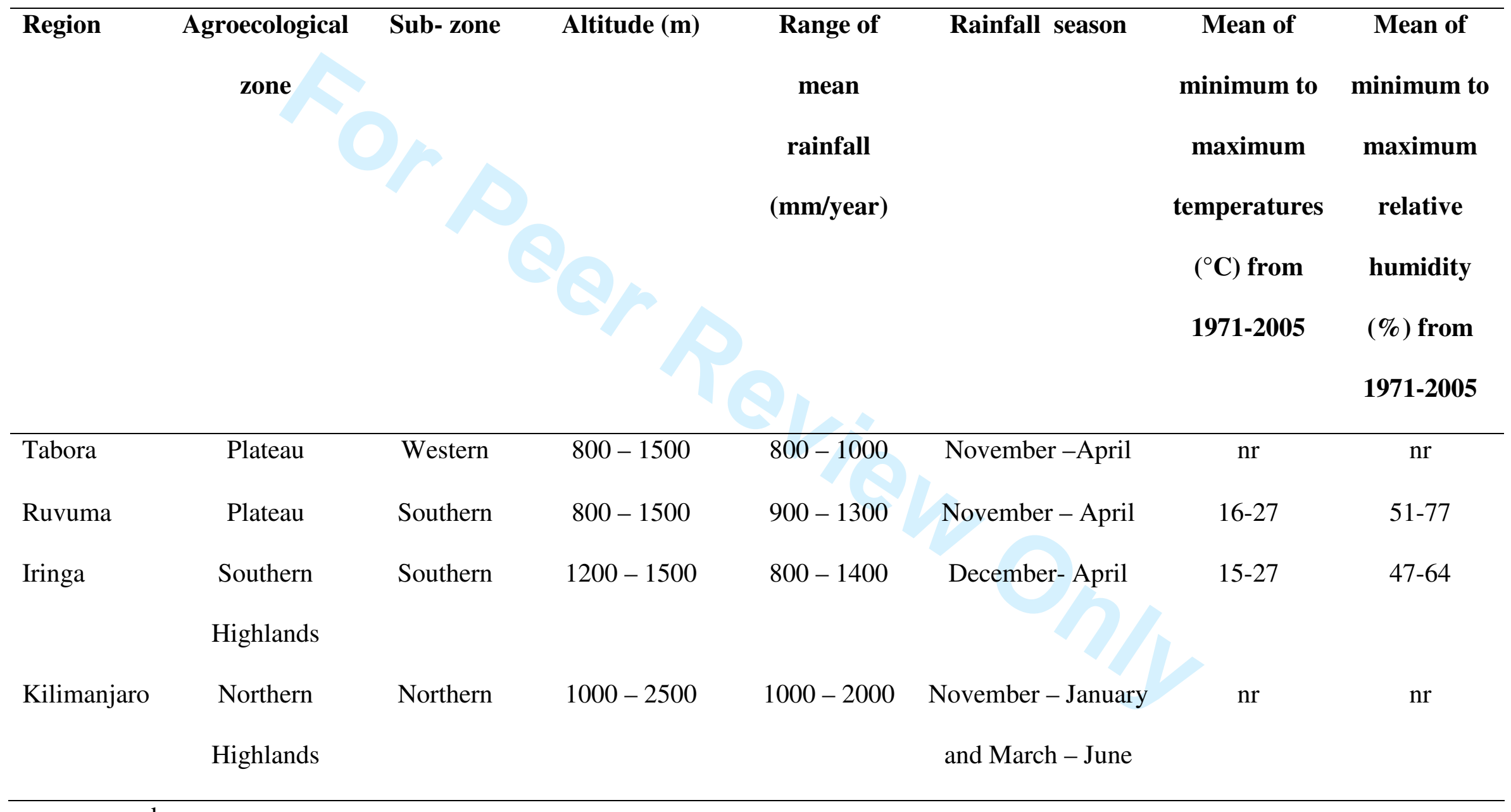

2 nr, no records 
5 Table II. Regional differences in number ${ }^{\text {a }}$ of households who sorted ${ }^{b}$ maize prior to storage and those who used part of the 6 damaged and mouldy maize as feed, local brew and food

\begin{tabular}{|c|c|c|c|c|c|}
\hline \multirow[t]{2}{*}{ Region } & \multirow{2}{*}{$\begin{array}{l}\text { Sorted prior to } \\
\text { storage }(\mathbf{n})\end{array}$} & \multirow{2}{*}{$\begin{array}{l}\text { Discarded damaged } \\
\text { and mouldy maize (n) }\end{array}$} & \multicolumn{3}{|c|}{ Used damaged and mouldy maize as } \\
\hline & & & Feed (n) & Liquor (n) & Food (n) \\
\hline Tabora & 26 & 1 & 1 & 0 & 24 \\
\hline Kilimanjaro & 30 & 0 & 16 & 2 & 12 \\
\hline Iringa & 26 & 4 & 7 & 7 & 8 \\
\hline Ruvuma & 28 & 16 & 6 & 0 & 6 \\
\hline Overall & 110 & 21 & 30 & 9 & 50 \\
\hline
\end{tabular}


Table III. Median fumonisin levels and occurrence of detectable samples at different contamination ranges in Tanzania

\begin{tabular}{|c|c|c|c|c|c|c|c|c|c|c|}
\hline \multirow[t]{3}{*}{ Region } & \multicolumn{3}{|l|}{$\mathbf{F B}_{1}$} & \multicolumn{3}{|l|}{$\mathbf{F B}_{2}$} & \multicolumn{4}{|c|}{ Total fumonisins } \\
\hline & \multirow[t]{2}{*}{$\begin{array}{l}\text { Median } \\
(\mu \mathrm{g} / \mathrm{kg})\end{array}$} & \multicolumn{2}{|c|}{$\begin{array}{ll}\text { Occurrence } & (\%) \text { at } \\
\text { different } & \text { ranges } \\
(\mu \mathrm{g} / \mathrm{kg}) & \\
\mathrm{LOD}^{\mathrm{a}}- & >1000^{\mathrm{b}}\end{array}$} & $\operatorname{Median}(\mu \mathrm{g} / \mathrm{kg})$ & $\begin{array}{l}\text { Occurrence } \\
\text { different } \\
(\mu \mathrm{g} / \mathrm{kg})\end{array}$ & $\begin{array}{l}(\%) \text { at } \\
\text { ranges }\end{array}$ & \multirow[t]{2}{*}{$\begin{array}{l}\text { Median } \\
(\mu g / k g)\end{array}$} & \multicolumn{3}{|c|}{$\begin{array}{l}\text { Occurrence }(\%) \\
\text { ranges }(\mu \mathrm{g} / \mathrm{kg})\end{array}$} \\
\hline & & $\begin{array}{l}\text { LOD }^{\mathrm{a}}- \\
\leq 1000\end{array}$ & $>1000^{b}$ & & $\begin{array}{l}\text { LOD }^{c}- \\
\leq 1000\end{array}$ & $>1000^{b}$ & & $\begin{array}{l}\text { LOD }^{\mathrm{d}}- \\
\leq 1000\end{array}$ & $\begin{array}{l}1000^{b} \\
\geq 4000\end{array}$ & $>4000$ \\
\hline Kilimanjaro & 363 & 30 & 14 & 323 & 30 & 10 & 524 & 30 & 7 & 7 \\
\hline Tabora & 257 & 60 & 10 & 131 & 47 & 3 & 363 & 53 & 17 & - \\
\hline Iringa & 145 & 30 & 13 & 291 & 30 & 3 & 501 & 30 & 13 & - \\
\hline Ruvuma & 144 & 37 & 13 & 485 & 14 & 6 & 155 & 37 & 13 & - \\
\hline Overall & 206 & 40 & 12 & 239 & 30 & 6 & 363 & 35 & 15 & 2 \\
\hline
\end{tabular}


1 Table IV. Occurrence and levels of $\mathrm{AFB}_{1}$ and total aflatoxins in maize in Tanzania

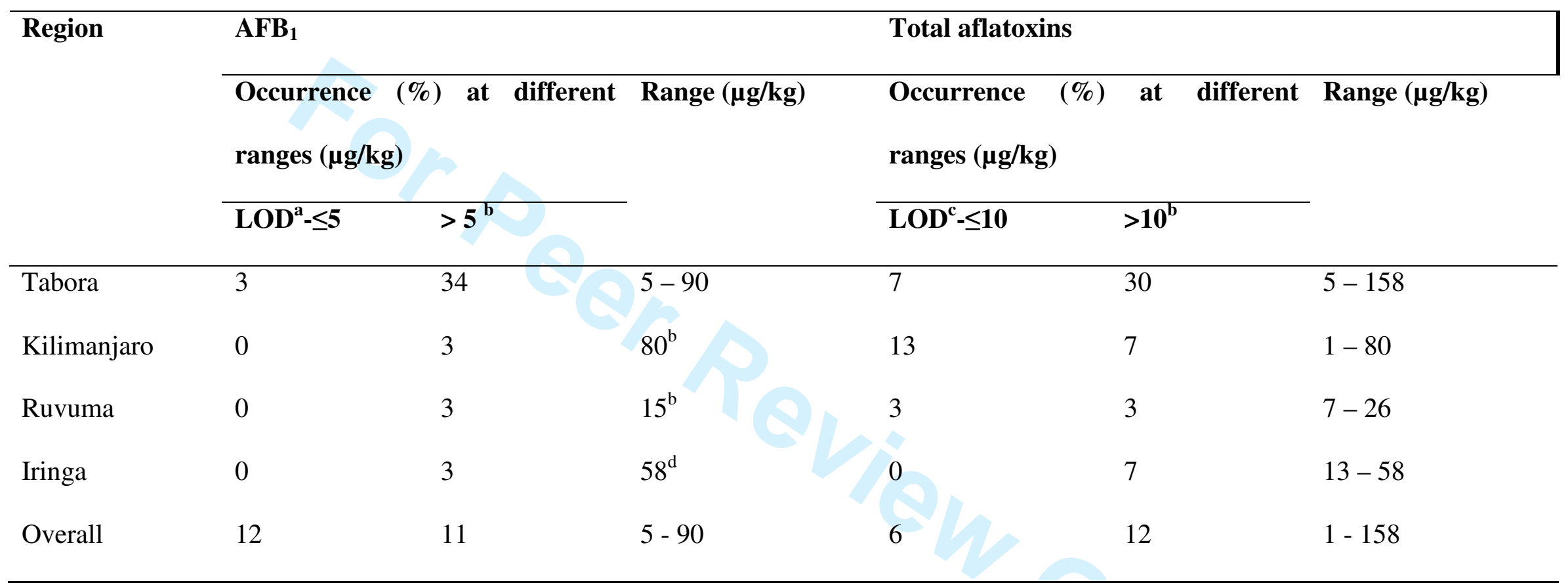

2 a , The limit of detection for aflatoxins $\mathrm{AFB}_{1} ;(0.6 \mu \mathrm{g} / \mathrm{kg}) ;{ }^{\mathrm{b}}$, MTL for $\mathrm{AFB}_{1}$ or total aflatoxins in maize for human consumption in

3 Tanzania; ${ }^{\mathrm{c}}$, The limit of detection for $\mathrm{AFB}_{1}$ or $\mathrm{AFG}_{1}(0.6 \mu \mathrm{g} / \mathrm{kg}), \mathrm{AFB}_{2}$ or $\mathrm{AFG}_{2}(0.07 \mu \mathrm{g} / \mathrm{kg})$ alone or in combination as the case may be;

4 d, one level present.

5

6 
3 Table V. Comparison of occurrence and levels of fumonisins and aflatoxins in maize with different levels of defective kernels

$4 \quad(\mathbf{n}=120)$

\begin{tabular}{llllll}
\hline Samples with defective kernels & & Total fumonisins & Total aflatoxins & \\
Percent defective kernels & No of samples & No of samples & Range $(\boldsymbol{\mu g} / \mathbf{k g})$ & No of samples & Range $(\boldsymbol{\mu g} / \mathbf{k g})$ \\
\hline$\leq 7^{\text {a }}$ & 15 & 5 & $143-685$ & - & - \\
$7<30$ & 88 & 43 & $61-5989$ & 14 & $1-158$ \\
$\geq 30$ & 17 & 12 & $65-11048$ & 8 & $1-151$
\end{tabular}

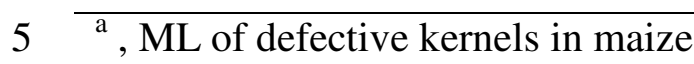


